\title{
Drivers of Subjective Well-being in Spain: Are There Gender Differences?
}

\author{
Rubén Arrondo $^{1}$ (D) Ana Cárcaba ${ }^{2}$ (D) Eduardo González $^{1}$ (D)
}

Received: 3 February 2020 / Accepted: 19 August 2020 / Published online: 1 September 2020

(C) The Author(s) 2020

\begin{abstract}
This paper explores the main drivers of subjective well-being(SWB) in Spain. Following current descriptions of SWB, the influence of a set of sociodemographic, material conditions and quality of life variables is empirically tested. The data come from a survey covering around 13,000 households and 35,000 individuals. The results show a very strong influence of material conditions on perceived SWB. Namely, the variable "income and wealth" is found to be the single major driver of satisfaction with life in the sample. Social connections, housing, and health status also emerge as very relevant drivers. Regarding the gender implications of SWB, our results show a paradoxical reality. On average, women score significantly lower than men in material conditions and quality of life variables, but they obtain significantly higher levels of SWB. Knowing the relevance of the different drivers of SWB may be helpful for the construction of composite indicators. We find that a SWB construct that includes only the most relevant drivers identified is a better predictor of actual SWB than the one that includes all the information available.
\end{abstract}

Keywords Subjective well-being · Life satisfaction · Quality of life · Spain · Gender

\section{Introduction}

Subjective well-being(SWB) is a "broad category of phenomena that includes people's emotional responses, domain satisfactions, and global judgements of life satisfaction" (Diener et al. 1999: p. 277). As such, it relates to social indicators of quality of life, but it also includes a subjective personal component that determines how the individual perceives the experience of life. Dissatisfaction with conventional measures of income

Eduardo González

efidalgo@uniovi.es

1 Department of Business Administration, University of Oviedo, Oviedo, Spain

2 Department of Accounting, University of Oviedo, Oviedo, Spain 
to measure social progress or individual well-being has promoted the interest of SWB analysis in the academic literature, extending to many different fields of research (wellbeing at work, health and well-being, gender gaps in well-being, etc.). This literature presents SWB as the most relevant goal for social development. John Lennon beautifully described the importance of the concept: "When I was five years old, my mother always told me that happiness was the key to life. When I went to school, they asked me what I wanted to be when I grew up. I wrote down 'happy'. They told me I didn't understand the assignment, and I told them they didn't understand life". Following this interest, many different measures of happiness and SWB have been developed worldwide, such as the OECD Better Life Index, the World Database of Happiness, or the Happy Planet Index. Even the 2019 World Economic Forum has dedicated a series of sessions to happiness and well-being.

In 2017, Spain scored an average 6.4 in the assessment of satisfaction with life within the Better Life Index, close to the global average of 6.5, ranking 24 out of the 38 OECD countries. Similarly, the United Nations World Happiness Report 2018 ranked Spain in the 36th position out of 156 countries, with a 6.3 average score on happiness (Sach et al. 2018). Nordic countries (Finland, Norway, and Denmark) typically occupy the first positions in these rankings. In contrast, according to the World Database of Happiness (Veenhoven 2004), directed by Ruut Veenhoven in the Erasmus University of Rotterdam, Costa Rica occupies the first position with an 8.5 on a $0-10$ scale, while Spain obtains a 7. Costa Rica also tops the Happy Planet Index, with a 44.7 score as of 2016 , with Spain in the 15 th position with a score of 36.0 . This latter index adds inequality and sustainability concerns to the measurement of SWB. Thus, overall, Spain belongs to the group of happy countries, reaching higher positions when inequality and sustainability are considered.

As noted from these initiatives, the term SWB is frequently used interchangeably for happiness. The subjectivity of the concepts of SWB or happiness is what distinguishes them from linked concepts such as the quality of life (QoL), which is rooted on measurable social indicators. However, both conceptualizations of welfare are closely related in the literature. Our approach in this paper comes from considering that the social indicators related to QoL are the main drivers that contribute to SWB. The main goal of the paper is to explore which are the main drivers of individual SWB in Spain. For this purpose, we focus on the description of current well-being as developed by the OECD in the Better Life Index initiative (Durand 2015). That proposal distinguishes between QoL and material conditions dimensions. QoL variables include Health status, Work-life balance, Education and skills, Social connections, Civic engagement and governance, Environmental quality, Personal security, and SWB. Material conditions include income and wealth, jobs and earnings, and housing. Our empirical model follows Boarini et al. (2012) by taking the SWB variable as dependent and the remaining QoL and material condition variables as independent forces driving the overall satisfaction with life. Additionally, we will also explore how sociodemographic variables such as gender, age, or region are associated with perceived SWB. It is of particular interest to determine the existence and importance of gender differences in the sample. Finally, we will examine how the selection of the most determinant drivers of SWB may help in constructing a more reliable composite indicator from social indicators. 


\section{Drivers of SWB}

Research on SWB is intimately interested in knowing the reasons why people are satisfied or dissatisfied with life. Although the personal experience of life is subjective and unique for each individual, the literature has identified some dimensions of life as having significant impact on SWB (Sirgy 2019). The seminal work of Wilson (1967) pointed to a list of drivers of SWB, attributing happiness to the young, healthy, welleducated, well-paid, extroverted, optimistic, worry-free, religious married person with high self-esteem, job morale, modest aspirations, of either sex, and a wide range of intelligence. The first three of these variables (health, education, and income) are traditional key dimensions of human well-being. Indeed, the Human Development Index (HDI), launched in 1990 by the United Nations, focused on these three major dimensions to compare social progress across countries. The aim of the HDI was to shift the focus of policy from economic growth to well-being development.

The first decade of the twenty-first century witnessed an increased interest in putting well-being at the center of the economic and social policy debate. The influential report of the Commission on the Measurement of Economic Performance and Social Progress (CMEPSP) placed the topic in the center of the social sciences agenda (Stiglitz et al. 2010). The report included a comprehensive analysis of the dimensions that shape people's well-being. To the three dimensions of the HDI, they added 5 more: personal activities including work, political voice and governance, social connections and relationships, environment and security (both physical and economic). Building on this description, the Better Life Index initiative of the OECD split some of those 8 dimensions, proposing a very complete framework based on 10 dimensions, as shown in Fig. 1. Material conditions include income and wealth, jobs and earnings, and housing. These are the variables more related to the economic performance of the individual. Then, quality of life dimensions include health status, work-life balance, education and skills, social connections, civic engagement and governance, environmental quality, and personal security.

While the manner in which each of these elements contributes to SWB may seem straightforward, the truth is that there is considerable controversy in the literature regarding some of them. Let us review briefly the main findings of empirical literature

\begin{tabular}{|c|c|c|}
\hline \multicolumn{3}{|c|}{ CURRENT WELL-BEING } \\
\hline & Quality of Life & Material Conditions \\
\hline - & Health status & - Income and wealth \\
\hline - & Work-life balance & - Jobs and earnings \\
\hline - & Education and skills & - Housing \\
\hline- & Social connections & \\
\hline- & Civic engagement and governance & \\
\hline- & Environmental quality & \\
\hline & Personal security & \\
\hline
\end{tabular}

Fig. 1 Drivers of SWB (adapted from the OECD's Better Life Index) 
on the relationship between these dimensions of quality of life and material conditions and SWB.

Some studies find a constant positive effect of income on life satisfaction at the individual level (Sacks et al. 2010), but the exact relationship between these two variables remains unclear. The literature review undertaken by Diener and BiswasDiener(2002) showed that the effect of income on SWB is positive when it implies avoiding poverty or living in a developed country. In contrast, the within country effects of income in developed nations seem to be small. The aspiration level of the individual moderates the effect of income and, in turn, past income drives aspiration levels. Therefore, "additional income for those who are not at low levels of income is unlikely to increase SWB in the long run if the additional income serves to increase the expectations of necessary income" (Dolan et al. 2008). This paradoxical effect of income was noted early by Easterlin $(1974,1995)$, who showed that wealthier individuals within a given society are happier, but happiness does not increase as income does. Once income is sufficient to make a good living, other factors contribute more to happiness, and the marginal effect of income becomes negligible. Comparisons are other strong moderating factor of income. Comparisons with others within the relevant social group (social comparisons) and comparisons to oneself in the past (habituation). Di Tella et al. (2010) find strong evidence of the small long run effect of an income shift (adaptation). It is relative income, more than income itself, what drives happiness (Clark et al. 2008). Not surprisingly, the effect of income on happiness is larger in transition than in developed countries. In addition to income, wealth also drives SWB by adding a sense of economic security (Jantsch and Veenhoven 2019). Given that our paper is cross sectional, focuses on individuals from the same country and measures SWB at the individual level, the relative effects of income on SWB are expected to be unambiguously positive.

In turn, the relationship between education and happiness is equally elusive. Graham (2012) explains that education may increase SWB by preparing individuals to better deal with the environment, but it also increases the aspiration levels of those individuals, which would decrease happiness. Some studies find a significant positive effect of education (Blanchflower and Oswald 2004). However, other studies find that the impact of education is weak after considering the effect of education on income and health (Helliwell 2008). Regarding health, the literature is less ambiguous. Both physical and psychological health are strong drivers of SWB (Dolan et al. 2008). Disability also has a lasting effect on life satisfaction (Lucas 2007).

The three variables involved in the HDI are, to a certain extent, correlated. Educated people tend to have better jobs and health habits. Richer people invest more in education and personal health. In addition, healthier people are able to obtain better jobs and higher education levels. For these reasons, the individual effect of each of these variables on SWB is very hard to isolate. There may also be important indirect effects among these variables. For instance, research has found important indirect effects of education on SWB through its effect on health (Bukenya et al. 2003; Gerdtham and Johannesson 2001).

As we discussed above, the Better Life Index adds some important dimensions to the HDI income-education-health triad. Starting with the material condition variables, with respect to the jobs and earning dimension, Clark and Oswald (1994), Oswald (1997), and Winkelman and Winkelman (1998) found that individuals rate the subjective cost 
of unemployment far higher than the corresponding loss of income. Furthermore, unemployed individuals do not return to their pre-unemployment levels of SWB when they find a new job (Lucas et al. 2004). Thus, it seems that it is unemployment, and not lacking a job, what reduces life satisfaction. Consistently, not working people which are not unemployed (retired, students, etc.) do not report lower levels of SWB (Blanchflower and Oswald 2004). On the other hand, the scarce evidence about the effect of housing on SWB is surprising (Boarini et al. 2012), given that the literature usually includes housing as a primary component of QoL and well-being.

With respect to the QoL variables (other than health and education, previously discussed), satisfaction with life relates strongly to the activities to which people devote their limited time. As noted earlier, the employed are happier than the unemployed, but the number of hours worked also has an effect on SWB. Meier and Stutzer (2006) found that there is an inverse U-shaped relationship between life satisfaction and hours worked. This is, full-time employment increases SWB over part-time employment, but only to the point that the number of hours worked becomes excessive. In other words, there must be a good balance between work and time for personal activities. Time spent in commuting is also a factor that reduces SWB by reducing the time available for either pleasant or productive activities (Stutzer and Frey 2005). In turn, caring for others has a negative impact on life satisfaction, which also explains the relatively low effect of having children on reported SWB (Dolan et al. 2008).

Civic engagement, i.e. involvement with the community, is believed to have positive effects on SWB (Helliwell 2003; Meier and Stutzer 2006). Regarding government and participation, Rodríguez-Pose and Maslauskaite (2012) found that good government exerts a positive influence on happiness. Good government and accountability of public administration also affect well-being positively at the municipal level of analysis (Frey and Stutzer 2000; Cárcaba et al. 2017).

Interaction and socialization with family and friends have highly positive effects on SWB (Kahneman and Krueger 2006; Lelkes 2006). Social support and trust in others are also relevant drivers of well-being(Helliwell and Wang 2011). Therefore, we expect a very positive influence of social connections on SWB.

Although the evidence in the literature is not quite extensive, the quality of the environment has been positively associated with SWB (Welsch 2002, 2006; Ferrer-iCarbonell and Gowdy 2007) and happiness (MacKerron 2012). Noise pollution also affects life satisfaction (Weinhold 2008). In turn, evidence suggests that, controlling for income differentials, living in an unsafe area negatively affects SWB (Lelkes 2006; Ferrer-i-Carbonell and Gowdy 2007; Balestra and Sultan 2013).

The literature on the driving forces of SWB in Spain is still scant. Requena (1995) explored the influence of the network of friends on SWB, finding a strong connection between both variables. The author also documents a positive effect of income on SWB. The influence of social connections on SWB has also been documented in García et al. (2002). They found that psychological well-being of immigrant women depended on the number of Spanish contacts in their personal support network. In the same line, Herrero et al. (2011) also showed the positive effect of personal relations on SWB for immigrant population in Spain. Cuñado and de Gracia (2012) analyzed the influence of education on happiness, finding a direct effect and also an indirect effect through income and job status. In a later paper, Cuñado and de Gracia (2013) explored the impact of pollution on SWB, showing significant regional differences in happiness, 
which can be partially explained by climate and air pollution. Working conditions are found to be an important driver of satisfaction with life.

This review of the literature shows that there is support for a positive relationship between the ten dimensions of the Better Life Index framework and SWB. This is the starting hypothesis to be tested in this paper:

- Hypothesis 1: There is a positive relationship between the 10 dimensions of the Better Life Index and SWB.

After exploring the empirical literature, Boarini et al. (2012) pointed to 4 dimensions of the Better Life Index as the most critical drivers of SWB: income and wealth, jobs and earnings, health status, and social connections. The remaining dimensions are expected to have positive but lower effects on SWB. In some cases, this may be due to the existence of indirect effects. For instance, education and skills may show a low direct effect on SWB, but been an important driver of income and wealth or jobs and earnings, which, in turn, are expected to be strongly related to SWB. This discussion leads to the first hypothesis of the paper:

- Hypothesis 2: The main drivers of SWB are income and wealth, jobs and earnings, health status, and social connections.

Apart from the dimensions of the Better Life Index framework, many demographic and personal characteristics have been considered to be related to SWB, such as gender, age, being immigrant, marital status, religiosity, having children, etc. (Dolan et al. 2008). The interest of our paper relies on assessing the effects of gender on SWB. However, we will also control for the effects of aging, marital status, and being immigrant.

Although some authors do not report a relevant gender effect on SWB (Louis and Zhao 2002), many other papers find women to be slightly happier than men, all else being equal (Alesina et al. 2004; Graham 2012; Yue et al. 2017). Since women tend to have lower income, are less educated, and report worse health status, it would be reasonable to expect that women be less happy. However, Zweig (2015) shows that, in most of the 73 countries analyzed, women are indeed happier than men are and report greater satisfaction with life. And the magnitude of this happiness gap does not seem to be related to the economic development of countries. Based on this evidence, when life conditions are similar, women should report higher levels of SWB.

This leads to the second hypothesis of the paper:

- Hypothesis 3: When controlling for differences in material conditions and quality of life dimensions, reported SWB should be higher for women than for men.

The literature also shows that the different traditional roles of men and women lead men to be less expressive emotionally and to link these emotions largely to power and status (Brody 1997). In contrast, women generally express more emotional and affective feelings, such as gratitude and happiness (Gordon et al. 2004; Yue et al. 2017). These behaviors may be attributed to gender roles which are still present in society, in which women are more sensitive to the needs of others and express their emotions more 
openly (Wood et al. 1989). These gender differences may be a function of different expectations of social roles, differences in socialization processes of men and women, cultural values, and the imbalance of power and status between genders. Thus, we may expect that the men's satisfaction with life be more closely related to material conditions variables such as income and earnings, while women's satisfaction with life will be more affected by quality of life variables such as social connections.

- Hypothesis 4: Men's satisfaction with life is more intensely driven by material conditions variables than women's.

As for age, while some studies have found a positive effect on SWB (Argyle 2013), other authors have proposed a U-shaped relationship (Clark and Oswald 1994; Ferrer-iCarbonell and Gowdy 2007; Blanchflower and Oswald 2008; Sujarwoto et al. 2018). The younger and the older would experience higher levels of SWB, while the lowest satisfaction with life would occur in middle ages.

- Hypothesis 5: There is a U-shaped relationship between age and SWB.

A classic driver of SWB is also marital status. Argyle and Furnham (1983) found that married people are happier, since marriage implies a strong form of social connection, which includes material and emotional support. These effects seem to extend also to the unmarried stable cohabiters (Brown 2000).

- Hypothesis 6: Cohabitating people tend to report higher levels of SWB, all else being equal.

Promoting the social integration of the immigrant population into society is a highly relevant goal in developed countries, since migration involves changes in many aspects of life. In general, immigrants tend to show lower levels of selfesteem and more stressing life experiences (Slonim-Nevo et al. 2009). They also need to rebuild social networks in the country of destiny (Monroe and Harkness 2005). These circumstances can negatively influence SWB even if material conditions are satisfactory. Several studies provide evidence that the social context in which the individual develops his or her life can have a determinant influence on subjective well-being(Davidson and Cotter 1991; Prezza and Costantini 1998; Herrero et al. 2011). Social integration considers both the individual's perception of being part of a larger community and the feeling of interdependence with other individuals in the same community (McMillan and Chavis 1986). Social integration in the community has a positive effect on SWB (Herrero and Gracia 2007). Frequently, the immigrant community compared with the national population has lower levels of social integration and more risk of social exclusion. For these reasons, empirical evidence shows that immigrants generally tend to be less satisfied with their life than natives (Vieno et al. 2009; Safi 2010; Shen and Takeuchi 2001).

- Hypothesis 7: Immigrants tend to report lower levels of SWB, all else being equal. 


\section{Data}

The data used in this paper come from the annual survey about living conditions in Spain, elaborated by the Spanish National Statistics Institute in 2013. We selected this year because the survey incorporated a specific block questionnaire of well-being, which has not been repeated since. The targeted population of the survey includes both households and individuals. Sample size is around 13,000 households and 35,000 individuals, selected through a two-stage stratified sampling method. Individuals were personally interviewed.

The survey includes two variables that can be used as reasonable proxies of SWB: satisfaction with life and life meaningfulness. The satisfaction with life variable measures the degree of satisfaction with the own life today in a scale from 0 (not satisfied at all) to 10 (fully satisfied). In turn, life meaningfulness measures the extent to what the individual considers that life is worth living in a scale from 0 (not worthy) to 10 (fully worthy). We believe the first of these variables (satisfaction with life) represents more closely the theoretical notion of SWB and common specifications of the concept in empirical literature. However, we think it is interesting to consider also the second variable (Life meaningfulness) for checking the robustness of the empirical results.

Figure 1 lists the 10 dimensions we considered as potential drivers of SWB. The value of our survey is that it contains information on a number of variables that can be used to approximate each of these dimensions. Starting with the material condition dimensions, we use the following proxies:

- Income and wealth: Satisfaction with the economic situation of the household (010 scale)

- Jobs and earnings: Unemployment (1 unemployed, 0 other situations $)^{1}$

- Housing: Satisfaction with the dwelling (0-10 scale)

We selected seven additional variables to account for the QoL dimensions listed in Fig. 1 :

- Health status: Perception of own health $(0-10 \text { scale })^{2}$

- Work-life balance: Satisfaction with leisure time (0-10 scale)

- Education and skills: Education attainment $(0-10 \text { scale })^{3}$

- Social connections: Satisfaction with personal relations (0-10 scale)

- Civic engagement and governance: Average of the trust in the political system, the legal system and the police $(0-10$ scale)

- Environmental quality: Average of satisfaction with green zones, recreation areas, and the surroundings of the house $(0-10$ scale)

\footnotetext{
${ }^{1}$ Then, a value 0 does not mean the individual is unemployed. (S)he could equally be retired, studying, or other personal not-working situations.

${ }^{2}$ The survey reports this variable on a 1-5 scale. A scale change was carried in order to homogenize all the variables to a $0-10$ scale. In all cases, in the modified scale 10 indicates the best possible value and 0 the worst one.

${ }^{3}$ The survey reports this variable on a $0-5$ scale. It was transformed to a $0-10$ scale.
} 
- Personal security: Perception of safety when walking at night around the living area $(0-10 \text { scale })^{4}$

To this list of variables, we added some socio-demographic variables, which have been related to SWB in previous literature and should be included in order to control such personal traits of the individual:

- Age: Expressed in years

- Gender: 0-man, 1-woman

- Cohabiting: 0-single, 1-married or cohabiting

- Immigrant: 0-national, 1-immigrant

Thus, we have collected information on two alternative SWB variables, three material condition variables, seven QoL variables, and four socio-demographic variables. A total of two alternative dependent variables and a list of 14 explanatory variables, four of them controlling for personal characteristics. Some filters were set in order to select the final sample for our study. First, given the nature of the description of well-being done in Fig. 1, we are only interested in the population between 18 and 65 (working age). Second, we imposed the condition that all the variables contained a valid value for each individual. After applying these filters, the final sample size was reduced to 19,002 individuals. Table 1 shows a description of the data for this sample.

The sample is almost equally split by gender and average age is 43 . The great majority of the individuals surveyed are Spanish nationals (90\%) and 63\% have a cohabiting partner. As for SWB, the variable satisfaction with life has an average value of 6.97 (a value which is very similar to the 2013 EU-28 average, which was 7.10). The variable life meaningfulness reaches a much higher average of 7.64. Therefore, it seems that respondents value the worthiness of life above their own satisfaction with that life.

Regarding the material conditions, respondents declare an average economic satisfaction of 5.75, even though there is a $22 \%$ unemployment rate. Satisfaction with the housing is higher and reaches an average of 7.32. As for the QoL variables, social connections, health status, and personal security are the best-evaluated dimensions obtaining a 7.84, 7.40, and 7.17 average values, respectively. On the contrary, civic engagement and governance obtain the lowest average (3.37), reflecting distrust with the political and legal system.

Table 2 reports mean differences between women and men. Important differences are detected for some of the variables. It is noticeable that, for both variables, women show higher SWB, being the difference very significant in life meaningfulness. Therefore, on average, women have a better self-perception of the meaning and purpose of life as compared with men. This result is in line with that observed in the literature and provides partial support for Hypothesis 3. Regarding the material conditions, there are no important differences, except that less women are unemployed. ${ }^{5}$ The QoL variables point to relevant differences regarding health, work-life balance, education and skills,

\footnotetext{
${ }^{4}$ The survey reports this variable on a 1-4 scale. It was transformed to a $0-10$ scale.

${ }^{5}$ Official Spanish unemployment rates for women and men in 2013 were $26.5 \%$ and $25.0 \%$, respectively. Our proportions do not reflect the actual situation of unemployment in Spain, since the variable counts the proportion of unemployed vs other categories (self-employed, employee, student, retired, disabled, etc.). Taking into account all possible categories, less women are actually unemployed.
} 
Table 1 Descriptive statistics

\begin{tabular}{|c|c|c|c|c|}
\hline Variable & Mean & $\mathrm{SD}$ & Min & $\operatorname{Max}$ \\
\hline \multicolumn{5}{|l|}{ SWB } \\
\hline Satisfaction with life & 6.97 & 1.95 & 0 & 10 \\
\hline Life meaningfulness & 7.64 & 1.71 & 0 & 10 \\
\hline \multicolumn{5}{|l|}{ Socio-demographic } \\
\hline Age & 43.08 & 13.02 & 18 & 65 \\
\hline Immigrant & 0.10 & 0.29 & 0 & 1 \\
\hline Gender & 0.51 & 0.49 & 0 & 1 \\
\hline Cohabiting & 0.63 & 0.48 & 0 & 1 \\
\hline \multicolumn{5}{|l|}{ Material conditions } \\
\hline Income and wealth & 5.75 & 2.23 & 0 & 10 \\
\hline Jobs and earnings & 0.22 & 0.41 & 0 & 1 \\
\hline Housing & 7.32 & 1.83 & 0 & 10 \\
\hline \multicolumn{5}{|l|}{ Quality of life } \\
\hline Health status & 7.40 & 1.93 & 0 & 10 \\
\hline Work-life balance & 6.37 & 2.37 & 0 & 10 \\
\hline Education and skills & 5.90 & 2.97 & 0 & 10 \\
\hline Social connections & 7.84 & 1.66 & 0 & 10 \\
\hline Civic eng. and govern. & 3.37 & 1,95 & 0 & 10 \\
\hline Environmental quality & 6.89 & 1.94 & 0 & 10 \\
\hline Personal security & 7.17 & 2.65 & 0 & 10 \\
\hline
\end{tabular}

civic engagement and governance, and personal security. Women report a significantly lower perception of personal security, health, and work-life balance than men. In contrast, they have higher educational attainment and more trust in the political and legal system. No significant differences are found in social connections or environmental quality. Finally, some of the socio-demographic variables also differ by gender. Women in the sample are slightly older than men, there is more representation of immigrant women, and there are more single men in the sample. All the differences shown in Table 2 support the paradoxical result found in previous literature. On average, women have a much lower perception of health, security, and work-life balance, while they are only slightly better in terms of unemployment, education, and civic engagement. However, women are consistently more satisfied with life than men (on average). The SWB production function of women seems to work more efficiently. We will check whether this result holds on when all the variables are accounted for simultaneously in the regression analysis.

Figure 2 shows the geographic distribution of satisfaction with life in Spain. The autonomous communities (ACs) with greater average life satisfaction are Baleares (7.45), Navarra (7.29), and Cataluña (7.21). On the opposite side, Galicia (6.20), Castilla y León (6.70), and Andalucía (6.75) present the lowest averages. Therefore, there is a concentration of SWB in the North-East of Spain, with large averages also in central regions (such as Madrid). The Western and Southern regions present the lowest scores. 
Table 2 Descriptive statistics by gender

\begin{tabular}{lccc}
\hline & Women & Men & \\
\hline$N \quad$ Mean & 9253 & $t$ test \\
$\quad$ Variable & & Mean & \\
SWB & 6.99 & & $1.69^{*}$ \\
Satisfaction with life & 7.73 & 6.94 & $7.5^{* * *}$ \\
Life meaningfulness & & 7.55 & \\
Socio-demographic & 43.24 & & $1.7^{*}$ \\
Age & 0.10 & 42.91 & $3.4^{* * *}$ \\
Immigrant & 0.64 & 0.09 & $2.7^{* * *}$ \\
Cohabiting & & 0.62 & 0.25 \\
Material conditions & 5.76 & & $-2.1^{* *}$ \\
Income and wealth & 0.21 & 5.75 & 0.78 \\
Jobs and earnings & 7.33 & 0.22 & \\
Housing & & 7.31 & $-7.6^{* * *}$ \\
Quality of life & 7.30 & & $-4.5^{* * *}$ \\
Health status & 6.30 & 7.51 & $5.6^{* * *}$ \\
Work-life balance & 6.02 & 6.46 & 0.42 \\
Education and skills & 7.84 & 5.78 & $2.5^{* *}$ \\
Social connections & 3.40 & 7.83 & -0.04 \\
Civic eng. and govern. & 6.90 & 3.33 & $-40.7^{* * *}$ \\
Environmental quality & 6.44 & 6.90 & \\
Personal security & 7.95 & \\
\hline
\end{tabular}

***Significance level $0.01 ; * *$ significance level 0.05 ; *significance level 0.1

\section{Empirical Results}

The proposed empirical model relates satisfaction with life with a number of driving forces related to QoL, material conditions of living, and socio-demographic variables. We estimated a hierarchical regression model in which each set of variables is introduced sequentially. The base model (model 1) includes only the sociodemographic variables (age, gender, immigrant status, cohabitation) as regressors. Then, the three material condition variables (income and wealth, jobs and earnings, and housing) are added in model 2. Finally, model 3 includes the remaining seven QoL variables (health status, work-life balance, education and skills, social connections, civic engagement and governance, environmental quality, and personal security). One technical consideration to be made is that the individuals in the sample are not completely independent, since all the members of each household are interviewed. In order to account for this feature of the data, we estimated clustered error regression models, in which households are the clusters.

Table 3 summarizes the results of the regression analysis. The base model, which includes only the socio-demographic variables, explains just a $4 \%$ of total variance in satisfaction with life. All the socio-demographic variables have the expected sign and are statistically significant at conventional levels. The positive coefficient of age and 


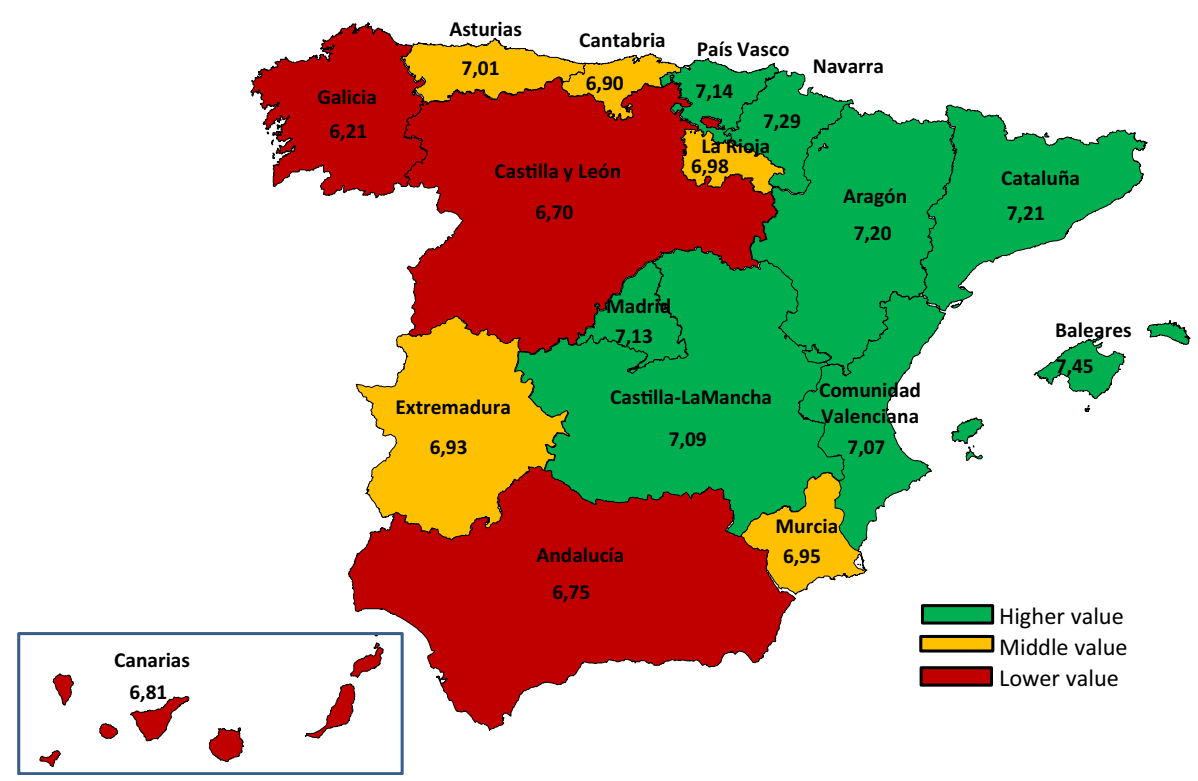

Fig. 2 The satisfaction with life map in Spain (full sample average: 6.97)

the negative coefficient of its square indicate a U-shaped effect of aging on SWB, as stated in Hypothesis 4. Immigrants seem to have lower SWB levels as compared with Spanish nationals in the base model. Finally, as expected, women and cohabiting partners are more satisfied with life than men and singles.

Some of the effects shown in the base model may disappear after including the material conditions and QoL variables, with which some socio-demographic variables may be correlated. For instance, Spanish nationals may be more satisfied with life because (on average) they have more income or education level than immigrants. In order to account for the effects of these correlations, we introduced the material conditions variables in model 2 and then the QoL variables in model 3. The effects of the material condition variables have the expected signs. Income and wealth has a positive and very significant effect, jobs and earnings (unemployment) has a very negative effect, and housing has a positive effect on life satisfaction. Regarding the socioeconomic variables, we see that the negative effect of immigration is insignificant once the material condition variables are controlled for in model 2. The effect of aging still shows the U-shaped form seen in model 1 , but now the quadratic term is insignificant. Therefore, the effect of aging on SWB would be negative (ceteris paribus the material conditions). Women and cohabiting partners still have significantly higher satisfaction with life even after accounting for differences in the material conditions variables. Model 2 explains an impressive $42 \%$ in total variance. Therefore, considering the material condition variables adds some $38 \%$ of explanatory power to the sociodemographic variables.

When the QoL variables are introduced (model 3), we find the expected (positive) effect in four of them: health status, work-life balance, social connections, and civic engagement and governance. In contrast, there is a negative effect of education and personal security, although these effects are statistically insignificant and, therefore, not 
Table 3 Drivers of SWB (dep variable: satisfaction with life)

\begin{tabular}{lccc}
\hline & Model 1 & Model 2 & \multicolumn{1}{l}{ Model 3 } \\
\hline Intercept & $8.76(56.6)^{* * *}$ & $3.67(24.8)^{* * *}$ & $0.560(3.7)^{* * *}$ \\
Socio-demographic & & & \\
Age & $-0.107(-13.9)^{* * *}$ & $-0.031(-5.16)^{* * *}$ & $-0.005(-0.9)$ \\
Age ${ }^{2}$ & $0.001(10.1)^{* * *}$ & $0.000(1.58)$ & $-0.000(-1.1)$ \\
Immigrant & $-0.505(-8.3)^{* * *}$ & $0.039(0.9)$ & $-0.008(-0.2)$ \\
Gender & $0.058(2.5)^{* *}$ & $0.034(1.78)^{* *}$ & $0.062(3.2)^{* * *}$ \\
Cohabiting & $0.760(19.2)^{* * *}$ & $0.444(14.5)^{* * *}$ & $0.355(12.5)^{* * *}$ \\
Material conditions & & & \\
Income and wealth & & $0.379(42.4)^{* * *}$ & $0.312(36.0)^{* * *}$ \\
Jobs and earnings & & $-0.307(-9.5)^{* * *}$ & $-0.403(-13.2)^{* * *}$ \\
Housing & $0.281(26.6)^{* * *}$ & $0.162(15.3)^{* * *}$ \\
Quality of life & & \\
Health status & & & $0.134(18.8)^{* * *}$ \\
Work-life balance & & & $0.043(6.9)^{* * *}$ \\
Education and skills & & & $-0.001(-0.13)$ \\
Social connections & & $0.275(28.1)^{* * *}$ \\
Civic eng. and govern. & & $0.045(7.5)^{* * *}$ \\
Environmental quality & & $0.009(1.2)$ \\
Personal security & 0.044 & $-0.000(-0.1)$ \\
$R^{2}$ & & 0.500 \\
\hline
\end{tabular}

$* * *$ Significance level $0.01 ; * *$ significance level $0.05 ; *$ significance level 0.1

different from zero. Environmental quality has a positive coefficient but it is equally insignificant. Therefore, it seems that these variables add little to the satisfaction with life or their effects are already accounted for by other variables with which they are correlated. We discussed above how education is intimately linked to income and health (the three variables in the HDI). It is common on empirical literature not finding a significant direct effect of education for this reason. In the same manner, personal security and environmental quality may be related to income and housing. Indeed, it seems that the QoL variables add little extra explanatory power to the material conditions variables, since the $R^{2}$ only increases to $50 \%$. Therefore, each QoL variable adds some $1 \%$ explanatory power to model 2 , while each of the material condition variables added more than $10 \%$ to model 1 .

It can be noted that, after controlling for the QoL variables in model 3, the effect of aging on SWB disappears completely. This indicates that, if there is some correlation between age and SWB, it is because both the material conditions and the QoL variables also change over time. Model 1 attributed these effects (incorrectly) to a consequence of aging. The effect of being an immigrant is also negligible in model 3, which suggest that if Spanish nationals are more satisfied with life, this is simply because they have better material and QoL conditions. In contrast, the effect of gender and having a cohabiting partner is positive and significant in the three models. The result confirms that women are significantly more satisfied with life even after all the other drivers of 
SWB are accounted for. Therefore, the results shown in Table 3 provide full support to hypotheses 3 and 5 and partial support to Hypothesis 1. The results also reject Hypothesis 4, since no significant relationship appears to hold with aging after all the other relevant variables are included in the specification of the model.

We have shown the effects of the different drivers of SWB through their effects on the dependent variable Satisfaction with life. In order to check whether the results are robust to the dependent variable chosen, we repeated the estimations using the variable life meaningfulness as a proxy of SWB. Recall that the individual answers to this question: do you think what you do in life is worth it? While it may seem closely related to the variable satisfaction with life, the correlation is only 0.56 . Therefore, this variable captures aspects of SWB not accounted for by the variable Satisfaction with life.

As shown in Table 4, the results are qualitatively identical to those obtained using satisfaction with life as the dependent variable. The only relevant difference (in model 3 ) is the significance of education and skills and personal security. While the correlation between education and life meaningfulness is positive (0.103), this variable seems to exert a negative influence on life meaningfulness, once the rest of the variables have been accounted for (health, income, etc.). This may reflect the increase in expectations that education bring to life. Once the positive effects of education (on income, health, etc.) are accounted for, the higher expectations lead to feelings of unworthiness. Personal security has the expected positive sign and now it is statistically significant.

Table 4 Drivers of SWB (dep variable: life meaningfulness)

\begin{tabular}{|c|c|c|c|}
\hline & Model 1 & Model 2 & Model 3 \\
\hline Intercept & $8.54(60.7)^{* * *}$ & $5.44(35.4)^{* * *}$ & $2.57(15.3)^{* * *}$ \\
\hline \multicolumn{4}{|l|}{ Socio-demographic } \\
\hline Age & $-0.057(-8.3)^{* * * *}$ & $-0.17(-2.66) * * *$ & $0.007(1.2)$ \\
\hline $\operatorname{Age}^{2}$ & $0.001(5.8)^{* * *}$ & $0.000(0.49)$ & $-0.001(-1.1)$ \\
\hline Immigrant & $-0.225(-4.2)^{* * * *}$ & $-0.105(-2.15)^{* *}$ & $0.065(1.4)$ \\
\hline Gender & $0.190(8.9)^{* * *}$ & $0.176(8.8)^{* * *}$ & $0.218(10.8)^{* * *}$ \\
\hline Cohabiting & $0.536(15.3)^{* * *}$ & $0.359(11.3)^{* * *}$ & $0.262(8.8)^{* * *}$ \\
\hline \multicolumn{4}{|l|}{ Material conditions } \\
\hline Income and wealth & & $0.167(20.6)^{* * *}$ & $0.112(14.3)^{* * *}$ \\
\hline Jobs and earnings & & $-0.116(3.5)^{* * *}$ & $-0.201(-6.4)^{* * *}$ \\
\hline Housing & & $0.233(23.4)^{* * *}$ & $0.118(11.8)^{* * * *}$ \\
\hline \multicolumn{4}{|l|}{ Quality of life } \\
\hline Health status & & & $0.102(13.3)^{* * *}$ \\
\hline Work-life balance & & & $0.030(4.7)^{* * * *}$ \\
\hline Education and skills & & & $-0.007(-1.8)^{*}$ \\
\hline Social connections & & & $0.279(26.0) * * *$ \\
\hline Civic eng. and govern. & & & $0.035(5.3)^{* * *}$ \\
\hline Environmental quality & & & $0.011(1.38)$ \\
\hline Personal security & & & $0.012(2.4)^{* *}$ \\
\hline$R^{2}$ & 0.025 & 0.186 & 0.274 \\
\hline
\end{tabular}

$* * *$ Significance level $0.01 ; * *$ significance level $0.05 ; *$ significance level 0.1 
From the results reported in Tables 3 and 4, we can confirm the positive and significant relationship between seven of the ten variables in the Better Life Index framework, namely, Income and wealth, jobs and earnings, housing, health status, work-life balance, social connections, and civic engagement and governance. Personal security also has the expected sign and significance in explaining life meaningfulness. In contrast, our results do not support the positive relationship between education and skills and environmental quality and SWB. Overall, these results provide empirical support for the Better Life Index framework, embedded in our Hypothesis 1. They also provide strong support for hypotheses 3 and 5, but not for Hypothesis 4 .

Once the drivers of SWB have been detected empirically, we turn to check which of the explanatory variables included in these models are more relevant in driving satisfaction with life. For this purpose, we rerun models 2 and 3 excluding each of the explanatory variables sequentially. Results are shown in Table 5.

As we can observe, Income and wealth is the one single variable with the highest explanatory power. If we exclude this variable from the specification, the $R^{2}$ drops by 0.13 in model 2 and 0.07 in model 3 . The second most relevant variable is social connections. By excluding this variable from model 3, the $R^{2}$ drops by 0.04 . Then, housing and health status are the third and fourth most important variables, with a similar effect on the $R^{2}$ of model 3. The effect of excluding the remaining variables is surprisingly small. In particular, there is no effect at all of excluding education and

Table 5 Explanatory power of the different drivers of SWB

\begin{tabular}{lccc}
\hline Excluded variable & & Model 2 & Model 3 \\
\hline Complete model & $R^{2}$ & 0.423 & 0.500 \\
Material conditions & & & \\
Income and wealth & $R^{2}$ & 0.289 & 0.425 \\
& $\Delta R^{2}$ & -0.134 & -0.075 \\
Jobs and earnings & $R^{2}$ & 0.419 & 0.494 \\
& $\Delta R^{2}$ & -0.004 & -0.006 \\
Housing & $R^{2}$ & 0.369 & 0.485 \\
& $\Delta R^{2}$ & -0.054 & -0.015 \\
Quality of life & & & \\
Health status & $R^{2}$ & & 0.486 \\
& $\Delta R^{2}$ & -0.014 \\
Work-life balance & $R^{2}$ & 0.498 \\
Education and skills & $\Delta R^{2}$ & -0.002 \\
Social connections & $R^{2}$ & 0.500 \\
Civic eng. and govern. & $\Delta R^{2}$ & -0.000 \\
Environmental quality & $R^{2}$ & 0.460 \\
Personal security & $\Delta R^{2}$ & -0.040 \\
& $R^{2}$ & 0.498 \\
& $\Delta R^{2}$ & -0.002 \\
& $R^{2}$ & 0.500 \\
& $\Delta R^{2}$ & -0.000 \\
& $R^{2}$ & 0.500 \\
& $\Delta R^{2}$ & -0.000 \\
\hline & & &
\end{tabular}


skills, environmental quality, and personal security. As we had already seen in Table 3, the effects of these variables on SWB were insignificant. So, either these variables are not important drivers of SWB or their correlations with the other four variables (the ones that condense a high explanatory power) are so strong that its isolated effect disappears when the other variables are accounted for. These results provide partial support for Hypothesis 1. Our revision of literature pointed to income and wealth, jobs and earnings, health status, and social connections. Three of them are indeed found to be the most relevant drivers of SWB in our sample. However, jobs and earnings is found to be less important than housing. Therefore, the four most important drivers of SWB in our sample are income, social connections, housing, and health status, by this order.

May this be different for men and women? In order to check for this possibility, we rerun model 3 separately for the subsamples of men and women. Table 6 contains the results of these estimations. The results match those obtained for the complete sample. Cohabitation appears to be the only socio-demographic variable with a significant impact on SWB for both men and women. Then, the three material condition variables and the four QoL variables identified before appear to be statistically significant with the expected sign. No effect of education, environmental quality, or personal security is found for either gender. So, when it comes to establish the sign and significance of the different drivers, we observe no important differences between genders. However, we found no relevant differences in the size of the effects. The most notable of these is the coefficient of jobs and earnings, which is 0.31 for women and 0.50 (56\% larger) for men. The results show that unemployment causes a significant reduction in SWB (independent from the income effect), but this reduction is much more severe for men than for women. Our explanation for this result is that, even though our society is giving great steps towards equality, there is still some division of roles which imply that men should provide for their families. Therefore, the psychological impact of being unemployed affects men more deeply since it exposes this traditional role to more danger. The rest of the coefficients are very similar for both genders, with women experiencing slightly higher levels of SWB associated to housing, health, or social connections and men to income and cohabitation.

We also noted some interesting differences in the explanatory power of some of the independent variables. The gender results for the $R^{2}$ and changes in the $R^{2}$ after excluding each of the variables from model 3 are presented in Table 7 . The global explanatory power in both subsamples is very similar, although slightly higher for women $(0.508$ versus 0.494$)$. The same four variables emerge as having the largest explanatory power as in the complete sample (income and wealth, housing, health status, and social connections). However, the relative importance of each of these variables is different for men and women. The loss of $R^{2}$ when excluding income and wealth is 0.081 for men and drops to 0.077 for women. ${ }^{6}$ In contrast, social connections have a much higher impact for women $(0.044)$ than men $(0.036)$. No relevant differences are appreciated for housing or health status, although the explanatory power is slightly higher for women in both variables. Therefore, while income is the single most important regressor for both genders, it seems that it is more critical for men. This may be associated with the same explanation offered above about

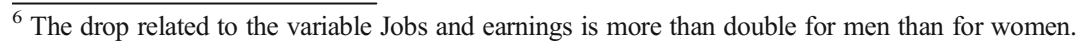


Table 6 Drivers of SWB by gender (dep. variable: satisfaction with life)

\begin{tabular}{lll}
\hline & Women & Men \\
\hline Intercept & $0.676(3.4)^{* * *}$ & $0.475(2.3)^{* *}$ \\
Socio-demographic & & \\
Age & $-0.004(-0.5)$ & $-0.007(-0.9)$ \\
Age ${ }^{2}$ & $0.000(1.2)$ & $-0.000(-0.4)$ \\
Immigrant & $-0.035(-0.7)$ & $-0.054(-0.9)$ \\
Cohabiting & $0.336(9.5)^{* * *}$ & $0.364(8.7)^{* * *}$ \\
Material conditions & & \\
Income and wealth & $0.303(27.9)^{* * *}$ & $0.321(27.3)^{* * *}$ \\
Jobs and earnings & $-0.310(-7.8)^{* * *}$ & $-0.500(-10.9)^{* * *}$ \\
Housing & $0.172(13.2)^{* * *}$ & $0.149(10.5)^{* * *}$ \\
Quality of life & & $0.132(12.9)^{* * *}$ \\
Health status & $0.137(14.2)^{* * *}$ & $0.043(4.9)^{* * *}$ \\
Work-life balance & $0.045(5.4)^{* * *}$ & $-0.001(-0.3)$ \\
Education and skills & $-0.001(-0.3)$ & $0.270(19.0)^{* * *}$ \\
Social connections & $0.279(21.9)^{* * *}$ & $0.048(6.0)^{* * *}$ \\
Civic eng. and govern. & $0.041(5.2)^{* * *}$ & $0.016(1.5)$ \\
Environmental quality & $0.003(0.3)$ & $0.011(1.5)$ \\
Personal security & $-0.007(1.1)$ & 0.494 \\
$R^{2}$ & 0.508 & \\
\hline
\end{tabular}

***Significance level $0.01 ; * *$ significance level $0.05 ; *$ significance level 0.1

the prevailing male role of providing (which is also consistent with the difference observed with respect to the variable Jobs and earnings). In contrast, the other three important variables add more explanatory power to women's life satisfaction.

Once the main drivers of SWB have been identified, we wanted to check how well these four main variables behave as predictors of SWB. For this purpose, we estimated a regression model including only the variables (income and wealth, housing, health status and social connections) and the socio-demographic characteristics. As shown in Table 8 , the $R^{2}$ only drops by 0.09 with respect to the complete model 3 that included all the explanatory variables available. ${ }^{7}$ The signs of the coefficients have the expected signs and only the quadratic effect of aging and the coefficient of immigrants are not statistically significant. Therefore, we believe this simplified model condenses the fundamental drivers of SWB. This does not mean that the excluded variables are irrelevant for SWB. For instance, Education is indeed an important potential driver of SWB and there are theoretical reasons to expect this relationship. However, our results suggest that it does so when it has an effect, for instance, on income and wealth or health status of the individual (Table 9).

\footnotetext{
${ }^{7}$ In the case of women, the $R^{2}$ is 0.501 ( 0.07 lower than in the full model). For men, it only drops to 0.481 ( 0.01 less than in the full model). Again, women seem to be slightly more sensitive to the multidimensionality of life satisfaction than men.
} 
Table 7 Explanatory power of the different drivers of SWB by gender

\begin{tabular}{llll}
\hline Excluded variable & & Women & Men \\
\hline Complete model & $R^{2}$ & 0.508 & 0.494 \\
Material conditions & & & \\
Income and wealth & $R^{2}$ & 0.431 & 0.413 \\
& $\Delta R^{2}$ & -0.077 & -0.081 \\
Jobs and earnings & $R^{2}$ & 0.504 & 0.486 \\
& $\Delta R^{2}$ & -0.004 & -0.009 \\
Housing & $R^{2}$ & 0.490 & 0.482 \\
& $\Delta R^{2}$ & -0.018 & -0.012 \\
Quality of life & & & \\
Health status & $R^{2}$ & 0.493 & 0.482 \\
& $\Delta R^{2}$ & -0.015 & -0.013 \\
Work-life balance & $R^{2}$ & 0.506 & 0.492 \\
Education and skills & $\Delta R^{2}$ & -0.002 & -0.002 \\
Social connections & $R^{2}$ & 0.508 & 0.494 \\
Civic eng. and govern. & $\Delta R^{2}$ & -0.000 & -0.000 \\
Environmental quality & $R^{2}$ & 0.464 & 0.458 \\
Personal security & $\Delta R^{2}$ & -0.044 & -0.036 \\
& $R^{2}$ & 0.507 & 0.492 \\
& $\Delta R^{2}$ & -0.001 & -0.002 \\
& $R^{2}$ & 0.508 & 0.494 \\
& $\Delta R^{2}$ & -0.000 & -0.000 \\
& $R^{2}$ & 0.508 & 0.494 \\
& $\Delta R^{2}$ & -0.000 & -0.000 \\
\hline & & &
\end{tabular}

Table 8 Most relevant drivers of SWB

Simplified model

Intercept

$0.731(5.0)^{* * *}$

Socio-demographic

Age

$-0.016(-2.9)^{* * * *}$

Age $^{2}$

0.001 (1.2)

Immigrant

$0.033(0.8)$

Gender

$0.064(3.5) * * *$

Cohabiting

$0.333(11.7)^{* * * *}$

Material conditions

Income and wealth

$0.351(42.0) * * *$

Housing

$0.173(16.6)^{* * * *}$

Quality of life

Health status

$0.136(19.0)^{* * * *}$

Social connections

$0.292(30.8) * * *$

$R^{2}$

0.491

***Significance level 0.01 
Table 9 Correlation between satisfaction with life and composite indicators

\begin{tabular}{lllll}
\hline & Satisfaction with life & Life meaningfulness & SWB4 & SWB10 \\
\hline Satisfaction with life & 1 & & & \\
Life meaningfulness & 0.56 & 1 & 1 & \\
SWB4 & 0.68 & 0.49 & 0.81 & 1 \\
SWB10 & 0.60 & 0.42 & & \\
\hline
\end{tabular}

Although the model explains roughly 50\% of the variance in SWB, there is still another half we cannot explain with socio-demographic, material conditions and QoL variables. We recall that SWB has to do with the personal experience of life and, therefore, cannot be fully explained with measurable variables. Each individual has his/ her own psychological perception of reality and a personal feeling of life satisfaction, which is affected but not completely determined by these variables. However, we can say that cohabiting or married people, with enough income, a nice housing, a satisfactory social life and good health can be expected to be much happier than people that score poorly on those variables.

As a final exercise in this paper, we wanted to check whether our results may be useful to guide the construction of composite indicators of SWB. The variables used here as regressors are often used as partial indicators of well-being in the construction of composite indicators. We can examine how well these variables behave as components of such composite indicators of SWB. For that purpose, we constructed two very simple composite indicators just adding up the values of the variables (all of them standardized to a $0-10$ scale). ${ }^{8}$ In other words, equal weights are imposed implicitly in the construction of the composite indicators. The advantageous properties of equal weighting in composite indicator construction have been stressed by Hagerty and Land (2007). The first indicator SWB4 includes only the four most relevant variables used in the simplified model (income and wealth, housing, health status, and social connections). The second indicator SWB10 includes all the 10 partial indicators in the Better Life Index framework.

As shown in Table 9, the correlation between SWB4 and satisfaction with life is surprisingly high (0.68), even higher than the correlation between satisfaction with life and life meaningfulness (our two proxy variables of SWB). The correlation with SWB10 is also large but significantly smaller (0.60). Interestingly, SWB4 also emerges as a better predictor of Life meaningfulness. These results point to two important aspects for the construction of composite indicators. First, a composite indicator of SWB may be even a better proxy of SWB than other variables that may seem to capture a similar reality (as is the case of life meaningfulness in our sample). Second, the composite indicator should contain only the most relevant information, as is the case of SWB4. Redundant information (as present in SWB10) produces double counting biases, which reduce the accuracy of the composite indicator.

\footnotetext{
${ }^{8}$ The unemployment variable was transformed in a way such that the employed obtain a score of 10 and the unemployed a score of 0 .
} 


\section{Concluding Remarks}

Subjective well-being is a concept of increasing interest in both society and academic literature. Traditionally, the measurement of quality of life has relied on objective indicators such as, for example, income, education, etc. In recent years, the volume of research that also includes subjective judgments, such as satisfaction with life, has increased. This paper explored the driving factors that best explain subjective judgments of life, approximated by the variables satisfaction with life and life meaningfulness. For that purpose, we used a large dataset of Spanish individuals and households.

Socio-demographic, material conditions and quality of life variables predict $50.1 \%$ and $27.4 \%$ of the variance in satisfaction with life and life meaningfulness, respectively. These results suggest that roughly half of the variance in the self-evaluation of SWB depends on psychological factors that operate beyond objective conditions of life. Interestingly, we find that women score higher in SWB perceptions, even though their objective conditions of life are slightly worse than those of men. The difference is even larger when we refer to life meaningfulness. In the case of men, SWB is strongly driven by income and wealth, which is also the primary driving force for women. However, other variables play a very important role in shaping women's SWB, especially social connections. Therefore, our results point to a more complex combination of factors driving SWB in women, as compared with men.

Contrary to the expectations, unemployment does not have a large and independent effect from that of the loss of income, as has consistently been reported in past literature. In our sample, when income and wealth are accounted for, the effect of unemployment on SWB is negligible.

Our results also shed some light for the construction of composite indicators of wellbeing. In particular, we show that including more variables in the construction of the composite indicators may worsen the accuracy of the index. A composite indicator including only the four most relevant variables (income and wealth, housing, health status, and social connections) correlated much better with the original proxies of SWB than the composite indicator that included the ten variables available. Therefore, it seems that including all the information available contributes to bias the composite indicator, as the same information is taken into account several times (i.e., double counting). This happens in particular when equal weights are employed, since the repeated information is equally weighted once and again. Other methods (BoD DEA weighting) may not suffer this problem so severely, because repeated information may receive small or even zero weights.

Even though our model explains a considerable portion of the variance in individual SWB (around 50\%), it also leaves much variance unexplained (the remaining 50\%). SWB is highly affected by the material conditions and QoL variables, but a large part of it depends on the personal perception of the individual and his/her psychological inclinations. An important limitation of our study is that, while we tried to control for some individual personal characteristics, the database does not contain enough information on important features that could not be considered. Aspects such as religiosity, ethnicity, nationality, children, etc. are not covered in our survey and therefore cannot be controlled for. Future research should try to isolate the effect of the material conditions and QoL variables, by controlling the individuals' traits. One way of doing 
this would be using panel data on a set of individuals. That type of data would allow the econometric estimation of a model including individual effects able to account for the unobserved heterogeneity associated to personal factors. Then, time variation in material conditions and QoL variables would determine the effects on satisfaction with life (ceteris paribus individual traits). Our purpose is to do this panel data estimation once the necessary data are available.

It would be desirable to pay further attention to the effects of aging on SWB. Our paper reports a small or even negligible effect of aging on SWB, but we restricted our analysis to working-age individuals. It would be convenient to extend this study with an exhaustive and methodical analysis of the particular indicators that influence SWB in the elderly (older than 65), which are not necessarily the same as the ones included in this study. A deeper focus on a sample of old people would be necessary to evaluate these differences.

Finally, another important limitation of our paper is the time period considered. The survey contains data obtained in 2013, when Spain was recovering from the strong recession caused by the 2008 financial crisis. The great importance of the material condition variables found in this paper may be contingent on the historical context. When more recent data are available, they should be analyzed in order to determine whether these findings are robust to changing economic conditions. Other external shocks could also have an impact on the relative importance of the different drivers of SWB. For instance, the incidence of the COVID19, with the associated confinement measures and restrictions to mobility, may increase the importance of QoL variables such as social connections or health status as self-perceived drivers of SWB.

Acknowledgments The authors gratefully acknowledge the Instituto Nacional de Estadística for providing access to the data without which this study would not have been possible. We also acknowledge the inspiring comments made by participants at the 17th ISQOLS annual conference that took place in Granada in September 2019.

Funding Information This research was financed by the Spanish "Ministerio de Ciencia, Innovación y Universidades", project code: MCIU-19-RTI2018-093669-B-I00 and co-financed with ERDF funds.

\section{Compliance with Ethical Standards}

Conflict of Interests The authors declare that they have no conflict of interest.

Human and Animal Rights This article does not contain any studies with human participants or animals performed by any of the authors.

Open Access This article is licensed under a Creative Commons Attribution 4.0 International License, which permits use, sharing, adaptation, distribution and reproduction in any medium or format, as long as you give appropriate credit to the original author(s) and the source, provide a link to the Creative Commons licence, and indicate if changes were made. The images or other third party material in this article are included in the article's Creative Commons licence, unless indicated otherwise in a credit line to the material. If material is not included in the article's Creative Commons licence and your intended use is not permitted by statutory regulation or exceeds the permitted use, you will need to obtain permission directly from the copyright holder. To view a copy of this licence, visit http://creativecommons.org/licenses/by/4.0/. 


\section{References}

Alesina, A., Di Tella, R., \& MacCulloch, R. (2004). Inequality and happiness: are Europeans and Americans different? Journal of Public Economics, 88(9-10), 2009-2042.

Argyle, M. (2013). The psychology of happiness. Routledge.

Argyle, M., \& Furnham, A. (1983). Sources of satisfaction and conflict in long-term relationships. Journal of Marriage and the Family, 45, 481-493.

Balestra, C., \& Sultan, J. (2013). Home sweet home: The determinants of residential satisfaction and its relation with well-being, OECD Statistics Directorate Working Papers 2013/05. Paris: OECD Publishing.

Blanchflower, D. G., \& Oswald, A. J. (2004). Money, sex and happiness: an empirical study. Scandinavian Journal of Economics, 106(3), 393-415.

Blanchflower, D. G., \& Oswald, A. J. (2008). Is well-being U-shaped over the life cycle? Social Science \& Medicine, 66, 1733-1749.

Boarini, R., Comola, M., Smith, C., Manchin, R., \& De Keulenaer, F. (2012). What makes for a better life?: the determinants of subjective well-being in OECD countries - evidence from the Gallup World Poll. In OECD statistics working papers, 2012/03. OECD: Publishing.

Brody, L. R. (1997). Gender and emotion: beyond stereotypes. Journal of Social Issues, 53(2), 369-393.

Brown, S. L. (2000). The effect of union type on psychological well-being: depression among cohabitors versus marrieds. Journal of Health and Social Behaviour, 41, 241-255.

Bukenya, J. O., Gebremedhin, T. G., \& Schaeffer, P. V. (2003). Analysis of rural quality of life and health: a spatial approach. Economic Development Quarterly, 17(3), 280-293.

Cárcaba, A., González, E., \& Ventura, J. (2017). Social progress in Spanish municipalities (2001-2011). Applied Research in Quality of Life, 12(4), 997-1019.

Clark, A. E., \& Oswald, A. J. (1994). Unhappiness and unemployment. The Economic Journal, 104, 648-659.

Clark, A. E., Frijters, P., Shields, M. A., \& M.A. (2008). Relative income, happiness, and utility: An explanation for the Easterlin paradox and other puzzles. Journal of Economic Literature, 46(1), 95-144.

Cuñado, J., \& de Gracia. (2012). Does education affect happiness? Evidence for Spain. Social Indicators Research, 108(1), 185-196.

Cuñado, J., \& de Gracia, F. P. (2013). Environment and happiness: new evidence for Spain. Social Indicators Research, 112(3), 549-567.

Davidson, W., \& Cotter, P. (1991). The relationship between sense of community and subjective well-being: a first look. Journal of Community Psychology, 19, 246-253.

Di Tella, R., Haisken-De New, J., \& MacCulloch, R. (2010). Happiness adaptation to income and to status in an individual panel. Journal of Economic Behavior and Organization, 76(3), 834-852.

Diener, E., \& Biswas-Diener, R. (2002). Will money increase subjective well-being? Social Indicators Research, 57(2), 119-169.

Diener, E., Suh, E. M., Lucas, R. E., \& Smith, H. L. (1999). Subjective well-being: three decades of progress. Psychological Bulletin, 125(2), 276-302.

Dolan, P., Peasgood, T., \& White, M. (2008). Do we really know what makes us happy? A review of the economic literature on the factors associated with subjective well-being. Journal of Economic Psychology, 29(1), 94-122.

Durand, M. (2015). The OECD better life initiative: how's life? And the measurement of well-being. Review of Income and Wealth, 61(1), 4-17.

Easterlin, R. (1974). Does economic growth improve the human lot? Some empirical evidence. In R. David \& R. Reder (Eds.), Nations and households in economic growth: essays in honor of Moses Abramovitz. New York: Academic Press.

Easterlin, R. (1995). Will raising the incomes of all increase the happiness of all? Journal of Economic Behavior and Organization, 27(1), 35-47.

Ferrer-i-Carbonell, A., \& Gowdy, J. M. (2007). Environmental degradation and happiness. Ecological Economics, 60(3), 509-516.

Frey, B. S., \& Stutzer, A. (2000). Happiness, economy and institutions. The Economic Journal, 110, 918-938.

García, M. F. M., Ramírez, M. G., \& Jariego, I. M. (2002). Social support and locus of control as predictors of psychological well-being in Moroccan and Peruvian immigrant women in Spain. International Journal of Intercultural Relations, 26(3), 287-310.

Gerdtham, U. G., \& Johannesson, M. (2001). The relationship between happiness, health, and socio-economic factors: Results based on Swedish microdata. Journal of Socio-Economics, 30(6), 553-557. 
Gordon, A. K., Musher-Eizenman, D. R., Holub, S. C., \& Dalrymple, J. (2004). What are children thankful for? An archival analysis of gratitude before and after the attacks of September 11. Journal of Applied Developmental Psychology, 25(5), 541-553.

Graham, C. (2012). Happiness around the world: the paradox of happy peasants and miserable millionaires. Oxford: Oxford University Press.

Hagerty, M., \& Land, K. (2007). Constructing summary indices of quality of life. A model for the effect of heterogeneous importance weights. Sociological Methods and Research, 35(4), 455-496.

Helliwell, J. F. (2003). How's life? Combining individual and national variables to explain subjective wellbeing. Economic Modelling, 20(2), 331-360.

Helliwell, J.F. (2008). Life satisfaction and quality of development, NBER Working Papers Series, ${ }^{\circ} 14507$, Cambridge, MA.

Helliwell, J. F., \& Wang, S. (2011). Weekends and subjective well-being. In Working paper 17180. Cambridge MA: National Bureau of Economic Research.

Herrero, J., \& Gracia, E. (2007). Measuring perceived community support: Factorial structure, longitudinal invariance and predictive validity of the PCSQ (Perceived Community Support Questionnaire). Journal of Community Psychology, 35, 197-217.

Herrero, J., Fuente, A., \& Gracia, E. (2011). Covariates of subjective well-being among Latin American immigrants in Spain: the role of social integration in the community. Journal of Community Psychology, 39(7), 761-775.

Jantsch, A., \& Veenhoven, R. (2019). Private wealth and happiness. In G. Brulé \& C. Suter (Eds.), Wealth(s) and subjective well-being. Social indicators research series (Vol. 76, pp. 17-50). Cham: Springer.

Kahneman, D., \& Krueger, A. B. (2006). Developments in the measurement of subjective well-being. Journal of Economic Perspectives, 20(1), 19-20.

Lelkes, O. (2006). Knowing what is good for you. Empirical analysis of personal preferences and the "objective good". The Journal of Socio-Economics, 35(2), 285-307.

Louis, V. V., \& Zhao, S. (2002). Effects of family structure, family SES, and adulthood experiences on life satisfaction. Journal of Family Issues, 23(8), 986-1005.

Lucas, R. E. (2007). Long-term disability is associated with lasting changes in subjective well-being: evidence from two nationally representative longitudinal studies. Journal of Personality and Social Psychology, 92(4), 717-730.

Lucas, R. E., Clark, A. E., Georgellis, Y., \& Diener, E. (2004). Unemployment alters the set point for life satisfaction. Psychological Science, 15(1), 8-13.

MacKerron, G. (2012). Happiness and environmental quality. Doctoral dissertation, The London School of Economics and Political Science.

McMillan, D., \& Chavis, D. (1986). Sense of community: definition and theory. Journal of Community Psychology, 14, 6-23.

Meier, S., \& Stutzer, A. (2006). Is volunteering rewarding in itself? Center for Behavioral Economics and. Federal Reserve Bank of Boston: Decision-Making.

Monroe, S. M., \& Harkness, K. L. (2005). Life stress, the" kindling" hypothesis, and the recurrence of depression: considerations from a life stress perspective. Psychological Review, 112(2), 417-445.

Oswald, A. J. (1997). Happiness and economic performance. The Economic Journal, 107(445), 1815-1831.

Prezza, M., \& Costantini, S. (1998). Sense of community and life satisfaction: investigation in three different territorial contexts. Journal of Community and Applied Social Psychology, 8, 181-194.

Requena, F. (1995). Friendship and subjective well-being in Spain: a cross-national comparison with the United States. Social Indicators Research, 35(3), 271-288.

Rodríguez-Pose, A., \& Maslauskaite, K. (2012). Can policy make us happier? Individual characteristics, socio-economic factors and life satisfaction in Central and Eastern Europe. Cambridge Journal of Regions, Economy and Society, 5, 77-96.

Sachs, J. D., Layard, R., \& Helliwell, J. F.. (2018). World Happiness Report 2018 (No. id: 12761).

Sacks, W. D., Stevenson, B., \& Wolfers, J. (2010). Subjective well-being, income, economic development and growth, NBER Working Paper No 16441. National Institute of Economic Research.

Safi, M. (2010). Immigrants' life satisfaction in Europe: Between assimilation and discrimination. European Sociological Review, 26, 159-176.

Shen, B. J., \& Takeuchi, D. T. (2001). A structural model of acculturation and mental health status among Chinese Americans. American Journal of Community Psychology, 29, 387-418.

Sirgy, M. J. (2019). What determines subjective material well-being? In G. Brulé \& C. Suter (Eds.), Wealth(s) and subjective well-being. Social indicators research series (Vol. 76, pp. 51-66). Cham: Springer.

Slonim-Nevo, V., Mirsky, J., Rubinstein, L., \& Nauck, B. (2009). The impact of familial and environmental factors on the adjustment of immigrants: a longitudinal study. Journal of Family Issues, 30(1), 92-123. 
Stiglitz, J., Sen, A., \& Fitoussi, J.P. (2010). Mismeasuring our lives: why GDP doesn't add up. New York: The New York Press.

Stutzer, A., \& Frey, B. S. (2005). Stress that doesn't pay: the commuting paradox. Scandinavian Journal of Economics, 110(2), 339-366.

Sujarwoto, S., Tampubolon, G., \& Pierewan, A. C. (2018). Individual and contextual factors of happiness and life satisfaction in a low middle income country. Applied Research in Quality of Life, 13(4), 927-945.

Veenhoven, R. (2004). World database of happiness. In Continuous register of scientific research on subjective appreciation of life.

Vieno, A., Santinello, M., Lenzi, M., Baldassari, D., \& Mirandola, M. (2009). Health status in immigrants and native early adolescents in Italy. Journal of Community Health, 34, 181-187.

Weinhold, D. (2008). How big a problem is noise pollution? A brief happiness analysis by a perturbable economist. MPRA Working Paper No. 10660.

Welsch, H. (2002). Preferences over prosperity and pollution: environmental valuation based on happiness studies. Kyklos, 55(4), 473-494.

Welsch, H. (2006). Environment and happiness: valuation of air pollution using life satisfaction data. Ecological Economics, 58(4), 801-813.

Wilson, W. (1967). Correlates of avowed happiness. Psychological Bulletin, 67, 294-306.

Winkelman, L., \& Winkelman, R. (1998). Why are the unemployed so unhappy? Evidence from panel data. Economica, 65, 1-15.

Wood, W., Rhodes, N., \& Whelan, M. (1989). Sex differences in positive well-being: a consideration of emotional style and marital status. Psychological Bulletin, 106(2), 249-264.

Yue, X. D., Jiang, F., Arjan, H. N., Jia, H., \& Su-Xia, L. (2017). How gender matters for happiness: A serial study in of college students in China. International Journal of Psychology \& Behavior Analysis, 2017.

Zweig, J. S. (2015). Are women happier than men? Evidence from the Gallup World Poll. Journal of Happiness Studies, 16(2), 515-541.

Publisher's Note Springer Nature remains neutral with regard to jurisdictional claims in published maps and institutional affiliations. 